25 ETHANE AND PENTANE IN EXPIRED AIR. MEASUREMENT OF LIPID PEROXIDATION IN SMALL PRETERM INFANTS. 0111 Pltkänen, Sture Andersson, and MIkko Hallman, Univ. Helsinki, Dept. Pediatrics, Helsinki, Finland Free oxygen radlcals are claimed to be of major

Importance in tissue damage in the newborn. Ethane (E) and pentane $(P)$ are specific products of free oxygen radical medlated lipld peroxidation (LIplds 12: 109-114 1977). We have quantifled these alkanes in expired air from 12 infants, gestation 25 to 31 weeks. All received mechanical ventllation and supplemental oxygen for treatment of RDS. After wash-out with hydrocarbon scrubbed alr $/ \mathrm{O}_{2}$ the explred alr was collected into a bag, trapped into Porasi ${ }^{2}-c$ adsorbent, and analyzed with internal standard by gas-chromatography.

During the first three neonatal days $E$ product ion ranged from 0 to 133 mol $/ \mathrm{kg} / \mathrm{min}$ and $P$ from 0 to $39.5 \mathrm{pmol} / \mathrm{kg} \mathrm{mln}$. $E$ and $P$ did not correlate well with the severity of the respiratory fallure or with the requirement of supplemental oxygen during the time of gas analysis. However, infants who eventually developed BPD $(n=2)$ or dled $(n=2)$, tended to produce more (63.4 $\mathrm{pmol} / \mathrm{kg} / \mathrm{min}$, range $0-133)$, and $P(29.1 \mathrm{pmol} / \mathrm{kg} / \mathrm{mln}$, range 12.9-39.5), compared to bables with a favourable prognosis: 22.9 $\mathrm{pmol} / \mathrm{kg} / \mathrm{min}(0-55)$ and $11.3 \mathrm{pmol} / \mathrm{kg} / \mathrm{mln}(0-22)$, respect ively. We propose that analysls of $E$ and $P$ is instrumental in studying the role of free oxygen radicals in diseases of the newborn. 26 FLOW BEHAVIOR OF NEONATAL AND ADULT ERYTHROCYTES IN A Stadler, T Böhler, E Zilow, O Linderkamp

Dept. of Pediatrics, Univ. Heidelberg, FRG.

This study was designed to analyse the flow behavior of red blood cells (RBC) by means of a mathematical model. According to this model, the flow resistance depends on the gap between RBC and vessel wall and on the plasma viscosity. Surface area (SA) and volume (V) of RBC from ten term neonates (N) and ten adults (A) were measured by means of a micropipette system and plasma viscosity (PV) was determined using a capillary viscometer. Neonatal RBC had larger $V$ and $S A$ than adult $R B C$ (107 6 vs $90^{ \pm 4} \mathrm{fl}$, and $154^{ \pm} 7$ vs $\left.137 \pm 7 \mathrm{~mm}^{3}\right)$. PV was lower in neonates $(1.04 \pm 0.10 \mathrm{cP})$ than in adults $(1.26 \pm 0.13 \mathrm{cP})$. The critical vesse? diameter below that the gap becomes too smali to allow sufficient lubrication is higher for neonatal RBC $(3.3 \mu \mathrm{m})$ than that for adult $R B C(2.9 \mu \mathrm{m})$. The driving pressure, hematocrit and viscosity of neonatal RBC is higher than that of adult RBC if both cell types have been suspended in the same medium. However, the driving pressure and viscosity of neonatal and adult $R B C$ is similar for neonatal and adult RBC if the cells have been suspended in the corresponding neonatal and adult plasma. We conclude that the flow properties of neonatal and adult RBC in vessels with diameters of 3.5 to $6 \mu \mathrm{m}$ are not different since the larger size of neonatal RBC is compensated by a lower PV.
lat
28 CHANGES IN CEREBRAL PEREUSTON DURING NEONATAL EXIRACORPOREAL MEMBRANE OXYGENATION. F. van Bel, F.J. Walther, E.S. Gangitano, J.R. Snyder. Univ. of Southem California, Huntington Memorial Hospital, Dept. of Neonatology, Ios Angeles, U.S.A.

To further understand the pattern of cerebral blood

flow during neonatal EOMO, we performed serial masure ments of the peak systolic (PSFV), end-diastolic (EDFV), and mean blood flow velocities (MFV) of the anterior cerebral arteries in 8 infants pre-, during, and post-ECMO. Mean + SD values of the MFV increased from $9.4+2.4 \mathrm{~cm} / \mathrm{sec}$ pre-BOMO to $13.0+2.2 \mathrm{~cm} / \mathrm{sec}$ ( $p<0.01)$ during maximal bypass flow $(91+17 \mathrm{ml} / \mathrm{min} / \mathrm{kg})$. Simulta-
neously, the mean EDFV increased from $4 . \overline{0}+1.9$ to $7.2+1.7 \mathrm{~cm} /$ $\sec (p<0.01)$, the mean PSFV increased from $10.3+1.9$ to $12.8+$ $3.1 \mathrm{~cm} / \mathrm{sec}$ (NS), and the pulsatility index (PI: PSFV-EDFV/PSFV) decreased from $0.63+0.12$ to $0.45+0.05$ (p<0.01). POst-ECMO values of $\mathrm{MFV}(8.4+2.5 \mathrm{~cm} / \mathrm{sec})$, EDFV $(3.8+1.4 \mathrm{~cm} / \mathrm{sec}), \mathrm{PSFV}$ $(9.3 \pm 2.5 \mathrm{~cm} / \mathrm{sec})$, and PI $(0.60+0.08)$ were comparable to pre ECMO values. During weaning from $\overline{\mathrm{D}} \mathrm{CMO}$ the PI increased steadily with a concomitant decrease of the MFV.

These data indicate that during neonatal EOMO cerebral perfusion is higher and cerebral vascular resistance lower than preand post-ECMO and that these changes are related to the amount of bypass used. 29 Ophthalmic Blood Plow Velocity (OBFV) in Sick Neonates.
Lindner $W$, Schindler M, Rlegel K, Versmold HT', Department of Pediatr. and Gyn. Ob. - Unlv. of Munlch, F.R.G. Abnormal pattern of cerebral BFV (CBFV) is known in neonates with diseases, associated with an increased risk of retinopathy of prematurity (ROP). No information risk of retinopathy of prematurity (ROP). No infortnall studied $O B F V$ and CBFV by pulsed Dopplersonography in 21 preterm (median gest. age 28 wks, range $24-32$ ) and 5 term neonates, with different problems, causing abnormal CBFV. (Patent ductus art. (PDA, $n=15$ ), Indomethacin $(n=1)$, polycythemia $(n=5)$, hypocapnia $(n=5)$, hydrocephalus $(n=1)$. 30 normal neonates (1), matched for $G A$ served as controls. Results: Changes In OBFV were always related to changes in CBFV. No Infant with abnormal CBFV had normal OBFV. PDA caused increased systolic and decreased or reverse diastolic OBFV. All other conditions were associated with a decrease in syst. and diast. OBFV. Mean OBFV decreased between 30 and $81 \%$ in polycythemic infants. The decrease was usually more marked in OBFV than in CBFV, however in hypocapnic infants mean OBFV was less decreased $\left(2 \%\right.$ / torr $\left.\mathrm{pCO}_{2}\right)$ than $\mathrm{CBFV}\left(4 \% /\right.$ torr $\left.\mathrm{pCO}_{2}\right)$.

Conclusion: Low OBFV is present in neonates with cllnical conditions causing decreased CBFV, this may cause abnormal retinal perfuslon. Thus, abnormal OBFV may be a risk factor for $\mathrm{ROP}$. $\mathrm{CO}_{2}$ reactivity of ophthalmic and cerebral arteries may be different. (1) Controls are partly presented in Pediatr Res 22:241 A, 1987. 27 EFFECT OF BLOOD TRANSFUSION ON BLOOD VOLUME, BLOOD Bauer $K$, Versmoid $H T$, Linderkamp 0

Women's Hospital Univ. Munich, Children's Hospital Univ. Heidelberg, FRG

Peripheral blood flow (PBF) depends on blood pressure

$(P)$, blood viscosity $(\eta)$ and vascular hindrance $(Z)$ : $P B F=P / R=P /(Z x \eta n)$, where $R$ is the peripheral resistance. Thus, $P B F=P / R=P /(2 \times n)$, where $R$ is the peripheral resistance. Thus,
blood transfusion can increase $P B F$ by increasing $P$ and decreasing $Z$ and decrease PBF by increasing $n$. We have studied PBF (venous occlusion plethysmography), $P$ (Doppler), blood volume (BV, Evans blue) and $n$ (capillary viscometer) in 14 anemic neonates (gestational age 27-42 weeks) during the first week of life immediately before and after transfusion (TX) of $20 \mathrm{ml}$ of whole blood.

\begin{tabular}{|c|c|c|}
\hline $\begin{array}{l}\text { BV }(\mathrm{ml} / \mathrm{kg}) \\
H c t(1 / 1) \\
\eta(\mathrm{cP}) \\
\mathrm{PBF}(\mathrm{ml} / \mathrm{min} \cdot 100 \mathrm{ml}) \\
P(\mathrm{mmHg}) \\
R(\mathrm{P} / \mathrm{PBF}) \\
Z(\mathrm{R} / \mathrm{n}) \\
\end{array}$ & $\begin{array}{l}87.6 \pm 15.4 \\
0.37 \pm 0.04 \\
2.9 \pm 0.3 \\
8.9 \pm 2.4 \\
73.0 \pm 16.1 \\
8.6 \pm 2.0 \\
2.9 \pm 0.7 \\
\end{array}$ & $\begin{array}{l}\text { post Tx } \\
96.8 \pm 12.7^{*} \\
0.47 \pm 0.04^{*} \\
3.6 \pm 0.3 \text { * } \\
11.9 \pm 2.5 \text { * } \\
82.6 \pm 19.1^{*} \\
7.6 \pm 1.6 \text { * } \\
2.1 \pm 0.5 \text { * }\end{array}$ \\
\hline
\end{tabular}

We conclude that $T x$ results in vasoditatation (decrease in $z$ ) and increased pressure, thereby increasing blood flow in spite of increasing blood viscosity.

\section{RENAL HANDLING OF SIALIC ACID (SA)}

Martin Renlund, Ra1l1 Seppälä, Frank Tietze, Isa Bernardini and Willtam Gahl. NICHD, NIH, Bethesda, MD, USA, and University of Helsinki, Finland

Sialic acid (SA) is mainly bound to glycoconjugates and is a component of glomerular membranes. Free SA is the most abundant negatively charged carbohydrate in urine. Salla Disease (SD) is a lysosomal storage disorder due to impatred egress of free SA from lysosomes. SD patients have 5-10 times elevated free $S A$ in their urine and plasma.

We determined the renal clearance of SA in controls and SD patients over a broad range of filtered loads, using an HPLC method. All patients had a normal creatinine clearance or glomerular filtration rate (GFR). The SA clearance approximated the GFR in all subjects, regardless of flltered load; hence, the fractional excretion jects, regardless of filtered load; hence, the fractional excretion
of SA was approximately $100 \%$. These results suggest that free SA is of SA was approximately $100 \%$. These results suggest that free SA is filtered by the kidneys and not reabsorbed, which contrasts markedly at plasma concentrations 1000 times that of free SA.

$$
\begin{aligned}
& \text { Plasma SA } \\
& \begin{array}{r}
(\mathrm{nmol} / \mathrm{ml}) \\
(\mathrm{X} \pm \mathrm{SD})
\end{array} \\
& \text { Controls }(n=9) \quad 0.80 \pm 0.28 \\
& \text { SD } \quad(n=8) \quad 4.13 \pm 2.48 \\
& \begin{array}{l}
\text { Fil tered Load } \\
\text { (nmol/min) } \\
\text { (range) } \\
\hline 39-72 \\
160-380
\end{array} \\
& \text { (\%) } \\
& \frac{(x \pm S D)}{95.2 \pm 14.4} \\
& 114.6 \pm 8.9
\end{aligned}
$$

